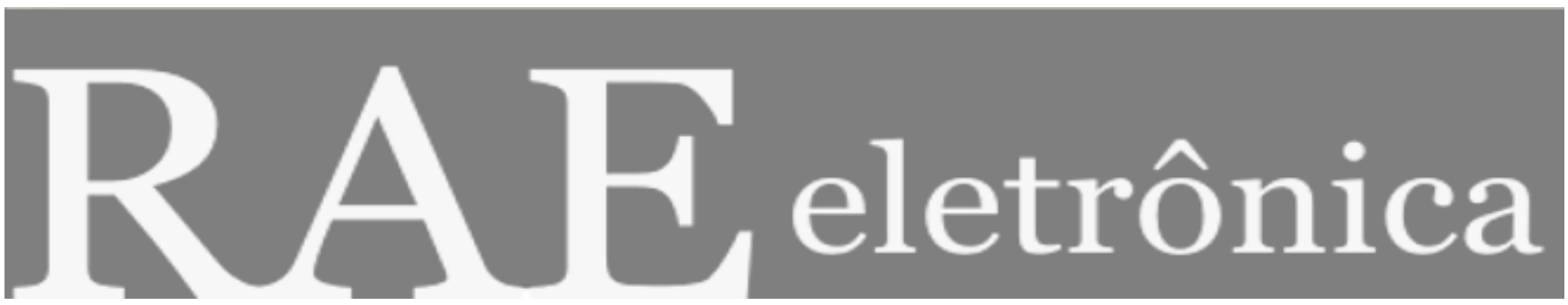

\title{
EDUCAÇÃO A DISTÂNCIA: O CASO OPEN UNIVERSITY
}

Por

\author{
Marta de Campos Maia \\ Fernando de Souza Meirelles
}

RAE-eletrônica, Volume 1, Número 1, jan-jun/2002.

http://www.rae.com.br/eletronica/index.cfm?FuseAction=Artigo\&ID=1426\&Secao=EDUCAÇÃO\&Volume=1\&Numero=1 $\& A n o=2002$

CCopyright, 2002, RAE-eletrônica. Todos os direitos, inclusive de tradução, são reservados. É permitido citar parte de artigos sem autorização prévia desde que seja identificada a fonte. A reprodução total de artigos é proibida. Os artigos só devem ser usados para uso pessoal e nãocomercial. Em caso de dúvidas, consulte a redação: redacao@,rae.com.br.

A RAE-eletrônica é a revista on-line da FGV-EAESP, totalmente aberta e criada com o objetivo de agilizar a veiculação de trabalhos inéditos. Lançada em janeiro de 2002, com perfil acadêmico, é dedicada a professores, pesquisadores e estudantes. Para mais informações consulte o site www.rae.com.br/eletronica.

RAE-eletrônica

ISSN 1676-5648

(C)2002 Editora: Fundação Getulio Vargas - Escola de Administração

de Empresas de São Paulo.

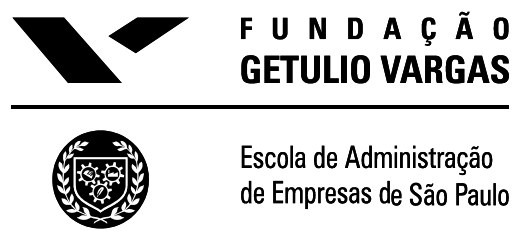




\section{EDUCAÇÃO A DISTÂNCIA: O CASO OPEN UNIVERSITY}

\section{Marta de Campos Maia}

Doutoranda em Administração de Empresas em Sistemas de Informação na FGV/EAESP e Pesquisadora do CNPq.

E-mail: mmaia@fgvsp.br

\section{Fernando de Souza Meirelles}

Vice-Diretor Administrativo e Professor Titular do Departamento de Informática e Métodos Quantitativos FGV-EAESP e Pesquisador do CNPq.

E-mail: meirelles@fgvsp.br

\section{RESUMO}

O crescente uso das tecnologias de informação e de comunicação está causando uma mudança significativa nas comunidades de aprendizagem em todo o mundo.

Com a ascensão de universidades virtuais, associadas a novos e criativos métodos de ensino dentro e fora do campus, profissionais do ensino superior depararam-se com uma série de novas oportunidades que estão sendo disponibilizadas no ensino superior.

Neste artigo estaremos analisando o modelo de ensino utilizado pela Open University do Reino Unido (OUUK), especificamente o curso de MBA, o seu processo e os efeitos do desenvolvimento de tecnologias educacionais, a fim de comparar suas práticas com o sistema educacional tradicional. A experiência de mais de trinta anos da OUUK em educação a distância, associada a um elevado nível de excelência acadêmica para um número muito grande de alunos, tem servido de modelo para instituições de todo mundo, que pretendem utilizar a educação a distância.

\section{ABSTRACT}

The increasing use of communication and information technologies is resulting in a significant change throughout learning communities around the world.

Through the rise of the virtual university, coupled with new and innovative methods of course delivery on and off campus, professionals in higher education are faced with a range of new opportunities approaching university teaching.

The purpose of this paper is to analyze the Open University of United Kingdom (OUUK) education model, in the MBA course, the process and the effects of developing educational technologies, to compare these ideas with the traditional education system.

OUUK' s long distance education experience of more than thirty years, associated to a high level of academic excellence for a impressive number of students has served as a model to institutions all over the world, which intend to use this kind of education.

\section{PALAVRAS-CHAVE}

Educação a distância, tecnologia educacional, ensino superior, modelos de educação a distância, tecnologia de informação.

\section{KEY WORDS}

Distance training, educational technologies, higher education, models for long distance education, information technology. 


\section{INTRODUÇÃO}

Educação a distância (EAD) é um desenvolvimento inovativo no ensino superior que usa a tecnologia para facilitar o aprendizado, sem as limitações de tempo ou de lugar. Uma comunidade de aprendizagem esteve tradicionalmente associada a uma localização física: uma escola, uma universidade, uma classe ou um laboratório. Com o advento da tecnologia, a nova noção de comunidade de aprendizagem moveu-se para o espaço virtual.

As universidades que oferecem cursos a distância são instituições que puseram o elemento humano em outro plano na equação de adição entre áudio e vídeo e, aulas e seminários face-a-face. Com a chegada da telemática, a comunicação pode ocorrer em diferentes momentos e locais e, como conseqüência, toda a noção da comunidade de aprendizagem mudou. Os alunos podem aprender em qualquer lugar no mundo.

Hoje, onze mega-universidades têm matriculado, mais de três milhões de alunos nos cursos de graduação e o desafio é aprender com essa experiência, a fim de avaliar e incentivar a inovação educacional.

Este estudo apresenta a metodologia adotada no curso a distância de MBA, no que diz respeito aos métodos face a face contrastando com a educação a distância. Embora o conceito de educação a distância não seja novo, os avanços da tecnologia oferecem um método mais robusto de ensino (Kerka, 1996). Estes avanços tecnológicos na EAD envolvem áreas como a instrução baseada na Internet, com os vários métodos de áudio e vídeo, e instrução síncrona e assíncrona.

A EAD não é nem recente e nem um novo fenômeno. Na realidade, a educação a distância existe há mais de um século desde os cursos de correspondência europeus, que foram as primeiras formas da educação a distância (Sherry, 1995). O que é novo é o desenvolvimento e a adoção de tecnologias cada vez mais sofisticadas de comunicação (Schlosser \& Anderson, 1994). Com o advento destas tecnologias, os programas de educação a distância estão se expandindo em uma taxa crescente (Weinstein, 1997). Entretanto, com freqüência, aqueles que elaboram os projetos dos cursos, tornam-se apaixonados pelas tecnologias e desconsideram importantes assuntos, especialmente as necessidades de aprendizagem dos alunos (Sherry, 1995).

\section{MODELOS DE EDUCAÇÃO À DISTÂNCIA}

O “Institute for Distance Education” (www.umuc.edu) propõe três modelos de EAD:

\section{a) Salas de Aulas Distribuídas}

Esse modelo estrutura-se a partir de tecnologias capazes de levar conhecimentos a pontos diferentes no mundo. A instituição responsável pelo treinamento controla o andamento e o local onde deverá ser realizado o treinamento. As aulas envolvem comunicação síncrona: instrutores e estudantes combinam local e horário para se encontrarem, uma vez por semana. As instituições são capazes de atender um pequeno número de alunos em cada local.

b) Aprendizado Independente

Nesse modelo os alunos podem fazer o curso independente do local onde estão e não têm que se adequar a escalas fixas de horário. Os estudantes recebem vários materiais de estudo, incluindo um programa do curso. A instituição coloca à disposição do aluno um monitor ou tutor que o acompanhará, fornecendo respostas e avaliando seus exercícios. A interação entre o monitor e o estudante é 
viabilizada através das seguintes tecnologias: telefone, fax, chats, correio eletrônico e correio tradicional. Não há aulas. Os alunos estudam de forma independente, seguindo fielmente o programa de curso. Os alunos podem interagir com o tutor e, em alguns casos, com outros estudantes. O curso é apresentado em forma de material impresso, CD-ROM, ou fitas de vídeo.

\section{c) Estudo aberto + Aulas}

Este modelo envolve a utilização de material impresso e outras mídias, tais como fitas de vídeo cassete ou disquetes de computador, que possibilitem ao aluno estudar no seu próprio local. Outras tecnologias que envolvam os alunos também poderão ser utilizadas. Os alunos se reúnem periodicamente em grupos, em locais específicos, para receber apoio instrucional. Nas aulas discutem-se os conteúdos, esclarecem-se conceitos, realizam-se trabalhos em grupos, experiências em laboratórios, simulações e outros exercícios relacionados com a aprendizagem.

\section{Modelo da Open University of United Kingdom}

O modelo de educação a distância utilizado pela OUUK é uma mescla entre os modelos de aprendizado independente e o modelo de estudo aberto. O curso é operacionalizado através de material impresso, em fitas de vídeo desenvolvidas em parceria com a rede de TV BBC, ou transmitido diretamente na $\mathrm{TV}$, quando em horários especiais, normalmente de madrugada, a BBC transmite os programas específicos para cada curso. Os alunos recebem o horário completo da programação dos vídeos da $\mathrm{BBC}$, juntamente com todo material impresso e as fitas de vídeo.

Desta forma, os alunos têm a liberdade de rever seus materiais quando bem entenderem ou necessitarem. Normalmente os materiais utilizados nesse modelo são resultado de um processo estruturado, que envolvem profissionais especializados em didática e especialistas nos assuntos a serem ensinados. Uma representação gráfica das estruturas didática e administrativas das universidades neste modelo é apresentada na figura 1.

\section{Figura 1: Modelo das Universidades de Educação a Distância}

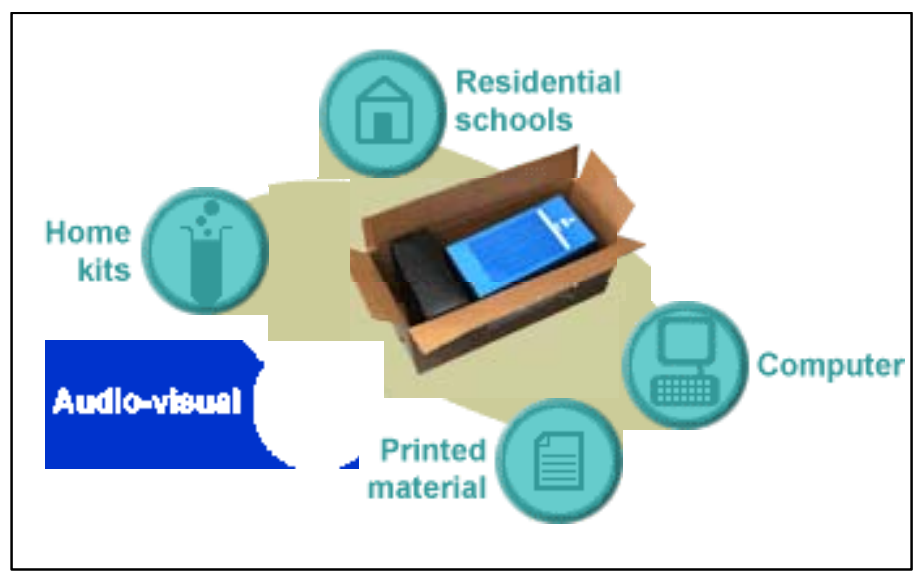

Fonte: Keegan, D. (2000)

Diferentes equipes participam do desenvolvimento dos cursos. Uma equipe projeta o pacote de aprendizagem completo, que compreende: o material impresso, o home kit, o material de televisão da $\mathrm{BBC}$, áudio e videocassetes e as estratégias de ensino.

A escola de Administração da OU oferece cursos a distância, de meio período no Reino Unido, Europa e outros locais. Os principais elementos deste modelo educacional são os materiais do curso: textos e audiovisual, além dos componentes que dão suporte a aprendizagem. 
Os componentes de cada curso são projetados para ajudar a aprender os conceitos, as idéias e as habilidades que o estudante precisa dominar no assunto escolhido, conforme figura 2.

Figura 2: Componentes do Curso

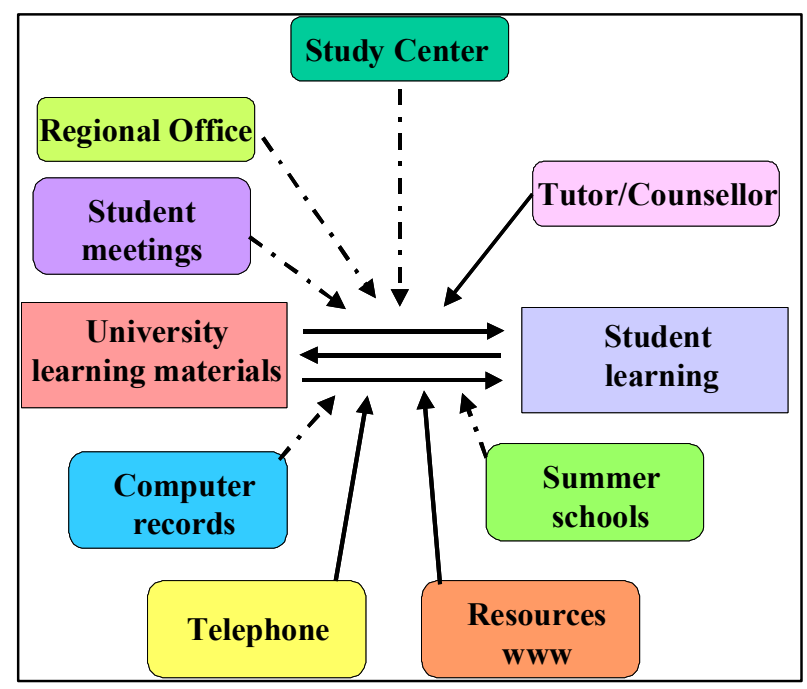

Fonte: The Open University site (2001)

\section{HISTÓRICO DA OPEN UNIVERSITY OF UNITED KINGDOM}

A Open University do Reino Unido (OUUK) foi criada pelo Royal Charter em 1969 e teve seus primeiros alunos matriculados em 1971. Desde essa data, mais de dois milhões de alunos já participaram de seus cursos.

A OU foi criada como uma instituição independente e autônoma, autorizada a conferir seus próprios títulos e empreender o treinamento profissional. Possuem permissão para conceder títulos na mesma base que outras universidades no Reino Unido.

Possuem escritórios regionais em todo Reino Unido e uma série de centros de estudo para atividades tutoriais dos estudantes. São, ao todo, cerca de 13 escritórios regionais e 306 centros do estudo no Reino Unido, além de 46 no exterior. Nos últimos anos, fizeram desenvolvimentos extensivos nos países da Europa central e oriental.

A escola de Administração da OU é a principal escola de Administração da Europa, além de ser o principal fornecedor de programas de Administração de Empresas a distância. Desde seu início, em 1983, mais de 150.000 alunos estudaram num dos cursos da escola de Administração da OU, quer seja na graduação ou no MBA. Atualmente a escola de Administração (OUBS) tem 30.000 estudantes no Reino Unido e em mais de 44 países.

A Open University of Business School (OUBS) obteve a acreditação do Instituto de Qualidade Europeu (EQUIS) da European Foundation for Management Development (efmd) em 2000, e foi a oitava escola britânica a passar pelo rigoroso processo de avaliação. Apenas 50 escolas têm este reconhecimento e a maioria delas está na Europa.

O programa do MBA foi acreditado pelo AMBA (a associação de MBAs) em 1994. Existem 110 escolas européias oferecendo MBA e apenas um terço tem este reconhecimento. Menos de 20 escolas 
no mundo têm o reconhecimento destes dois órgãos, o que comprova a validade externa do ensino da Open University.

\section{METODOLOGIA DE ANÁLISE DO CASO}

A metodologia utilizada no trabalho foi a de estudo de caso, devido às questões básicas de pesquisa, ausência de controle dos eventos comportamentais e ênfase nos eventos contemporâneos. O estudo considerou e respeitou os vários aspectos, condições, recomendações, componentes e requisitos, definidos por vários autores, dentre eles Yin (2001). Um estudo de caso é um questionamento empírico que investiga um fenômeno contemporâneo com seus contextos de vida real, quando as fronteiras entre fenômeno e contexto não são claramente evidentes, e nos quais fontes múltiplas de evidência são usadas, segundo Yin (2001).

Trata-se, portanto, de uma pesquisa empírica, porque pretende fazê-lo através do estudo de caso real. A aplicação da metodologia de estudo de caso foi realizada por meio de entrevista e utilizou um protocolo elaborado especificamente para este fim. Este protocolo considerou a necessidade de conhecer a organização e as metodologias educacionais adotadas.

As questões básicas da pesquisa são:

$>$ Quais processos educacionais permeados pela tecnologia de informação são utilizados nos cursos de EAD? Identificar como e qual a abrangência do uso da TI, em relação às seguintes questões:

○ Qual o grau de interação dos alunos com os professores do curso?

○ Quais as formas e freqüência de comunicação entre professores e alunos?

○ Quais as tecnologias de ensino utilizadas?

○ Quais as principais funcionalidades são oferecidas como ferramentas de suporte aos alunos?

○ Como são preparados e distribuídos os materiais usados?

○ Quais os critérios de avaliação adotados?

A entrevista foi realizada no início de 2001, com Mr. Richard H. Wheatcroft, MBA Programme Director, em Milton Keynes, England, campus principal da OUUK.

\section{ANÁLISE DO CASO}

\section{Identificando a Estratégia da EAD na Open University}

O programa do MBA é projetado para gerentes de nível médio e sênior. A ênfase do curso está na análise estratégica, em habilidades interdisciplinares e no julgamento independente. Os cursos são consideravelmente mais exigentes do que aqueles programas profissionalizantes da escola de Administração da $\mathrm{OU}$ e pressupõem uma base de conhecimento adquirida da experiência prática, precedente no cargo de gerência. 
No MBA, pela própria natureza dos alunos, você encontrará questões do tipo: como você analisaria a sua própria empresa, como compararia com sua experiência pessoal? O curso está continuamente tentando ligar a teoria do material escrito à prática em suas mentes.

Os alunos em geral são pessoas maduras. A idade mínima para o MBA é 27 anos. A média de idade é 33. Isso significa que aqueles que fazem o MBA estão ocupados com suas próprias carreiras, tem família, prestação da casa, e outras obrigações.

\section{Metodologia de Ensino}

Os cursos são desenvolvidos por equipes de cursos. Um primeiro curso pode ter como equipe 20 funcionários em tempo integral da Open University ou da $\mathrm{BBC}$ e, a esta equipe associam-se consultores, os responsáveis pelo desenho instrucional e os peritos de mídia. Uma equipe projeta um pacote de aprendizagem completo que compreende o material impresso, o home kit, o material de televisão da BBC, áudio e videocassetes e estratégias de ensino.

O material impresso inclui geralmente: os textos que descrevem, explicam e desenvolvem as idéias, a informação e os conceitos chaves explorados no curso; materiais que ajudam a organizar o estudo, tal como um calendário do curso no qual o aluno anota o que deve estudar e quando e, os materiais para ajudar a completar as avaliações, explicando em detalhe o que o aluno necessita fazer para cada atribuição e sugerir como resolver.

O curso do MBA inclui material audiovisual para dar suporte ao aprendizado do aluno. Os vídeos contêm uma visão geral do tema a ser apresentado; explora os conceitos e idéias complexas do assunto, no contexto real, através de exemplos. O material é transmitido pelo canal de TV da BBC ou então, é emitido ao aluno em forma de um vídeo ou audiocassette.

Todo o aluno, de todos os cursos, tem que ter um orientador (tutor) local. Calculam uma média de 15 a 20 alunos por orientador. São recrutados administradores e executivos locais ou professores de escolas de Administração onde os alunos estão, para dar o suporte necessário.

Em Londres, por exemplo, há cerca de quatro a cinco grupos de orientadores. Na Escócia e em outras partes da Europa, os orientadores trabalham em um raio de cerca de $150 \mathrm{~km}$ de distância. A OUUK procura fazer com que pelo menos na Grã-Bretanha, os alunos não fiquem a uma distância maior do que uma hora de carro de seus orientadores.

A presença nos seminários é voluntária e estes acontecem a cada seis semanas. Os seminários de grupos de orientadores diferentes são organizados de forma a ocorrer em dias diferentes. Assim, se o aluno não puder ir ao seminário do seu grupo, vai ao de outro grupo. Tenta-se dar oportunidades para que todos alunos trabalhem em redes de contato, por isso é enfatizado o caráter voluntário.

Nos seminários são distribuídos materiais especiais dos orientadores. Ele contém os assuntos que os alunos devem trabalhar nesse estágio do curso. O que é importante saber é que não há palestras. A OUUK não utiliza o título de palestrante nos seus cursos. Em um seminário tutorial típico de três horas espera-se que o orientador não fale mais que 20 ou 30 minutos, ou talvez faça uma pequena introdução sobre um tópico em particular. Então há uma atividade onde se formam grupos de quatro ou cinco pessoas que recebem uma tarefa para fazer, por exemplo, um estudo de caso. 
Os alunos vêm de longe e querem interagir, algumas vezes com o orientador e, algumas vezes uns com os outros, e é muito importante fazer com que as pessoas dêem contribuições, pois desta forma estão aprendendo por experiência.

Os seminários não são transmitidos por e-mail ou telefone, e o contato do aluno com os profissionais do curso se dá através do orientador e não no centro em Milton Keynes. Do total de 30.000 alunos matriculados na Open University Business School (OUBS), aproximadamente 6.500 alunos são alunos do MBA e, nem todos estes alunos podem se deslocar até o centro principal da universidade.

A universidade fornece facilidades para pesquisas, como biblioteca, laboratórios, computadores e assim por diante, para estudantes internos que se dedicam em tempo integral ou em meio período.

Dentro do programa de aprendizado à distância, há ainda os cursos de verão e as escolas residenciais. Normalmente os alunos chegam numa sexta-feira à tarde e saem domingo à noite. É um programa bastante intensivo de dois dias e meio. Estes encontros são organizados em universidades, hotéis e etc. Nas escolas residenciais são utilizados vídeos, áudios e CD-ROM. Mas, o material entregue aos alunos não é só o impresso, pois existem os vídeos, estudos de caso e outras atividades.

\section{Currículo e Prazo}

O prazo mínimo para cursar o MBA é de três anos. É muito difícil, para alguém que tenha uma carreira, ser capaz de estudar todo o material em menos de três anos. Há pessoas que o cursam em menos tempo, mas porque só trabalha três dias por semana ou só meio período.

Considerando, que para um curso de MBA espera-se que o aluno estude de 10 a 12 horas por semana, é muito difícil acelerar este ritmo. Por isso a política rígida da OUUK em não deixar que os alunos façam mais de um curso de cada vez, pois os alunos não fariam nenhum deles de forma adequada.

A OUUK oferece outros cursos que, tem em termos de duração normal, nos termos americanos, oito horas-crédito (trezentas horas de trabalho). Há também cursos curtos, de quatro horas-crédito, em que também se faz provas de três horas. Novos cursos mais curtos estão sendo experimentados, com provas de uma ou duas horas.

\section{Recursos e Suporte para o Aprendizado}

\section{A OUUK fornece:}

- tutor - responsável por dar suporte um grupo pequeno de estudantes do curso. Um orientador que siga o progresso do estudante durante toda a sua carreira e um tutor para o aconselhamento em um curso individual;

- 13 escritórios regionais que fornecem um foco descentralizado para a administração da taxa de matrícula, aconselhamento e sistemas de apoio aos alunos. O estudante pode entrar em contato com o centro regional pelo telefone, por e-mail ou por carta ou agendando uma visita;

- um centro do estudo de fácil acesso onde o estudante pode se encontrar com outros alunos e utilizar as facilidades oferecidas; 
- $\quad$ equipe de funcionários da OU que fornecem conselho e orientação em assuntos como a escolha do curso, como se registrar, orientação de carreiras, e progresso do estudo.

No caso de uma pessoa ir para um lugar muito afastado, fica claro que ela não terá o mesmo suporte, já que os orientadores não vão estar há $100 \mathrm{~km}$ de distância, mas há milhares de quilômetros. Mas, de qualquer forma há aqueles alunos que se comunicam com seus orientadores só por e-mail ou telefone. A OUUK, por exemplo, possui um programa de MBA estrangeiro no Cazaquistão. Alguns dos alunos trabalham em multinacionais e são transferidos para várias partes do mundo, como o Cazaquistão, às vezes por um período de um ano. Neste caso, o orientador poderá estar na Europa, mas, mesmo assim, é ele quem vai dar o suporte e as notas nos trabalhos do aluno.

A OUUK conta, atualmente, com mais de oitocentos orientadores.

\section{Alunos}

A OU não tem nenhuma exigência para a entrada de alunos nos cursos de graduação. Quase todos os estudantes da OU estudam em meio expediente e aproximadamente $70 \%$ são empregados. A idade média de um estudante da OU é 37 anos, mas o mais novo aluno da pós-graduação tinha 20 e o mais velho acima 90.

Para aqueles que não tem diploma, nem certificado em administração, geralmente é aconselhado a não cursar o MBA. No entanto se eles quiserem, a escolha é deles, ainda que possa estar errada. A OU é uma universidade aberta, em todos os cursos, e acredita em medidas de "output" e não de "input".

\section{Material de Ensino}

Os alunos recebem todo o material em casa, um conjunto completo em uma caixa. Nesta caixa eles encontram, entre outros, textos e um livro texto padrão de algum autor renomado. A OU apenas compra da editora, como qualquer outra universidade, e distribui aos alunos.

Alguns livros são compilados pela própria universidade, ou seja, são específicos do curso e só os alunos recebem. Há ainda os que são produzidos pela $\mathrm{OU}$ em associação com um dos cursos e estes são publicados e colocados no mercado. De qualquer forma, todo material necessário é enviado na caixa. Não se espera que os alunos tenham que procurar outros livros, pois estes são os textos centrais. É crucial perceber e trabalhar com o fato de que os alunos não moram num campus universitário.

O material distribuído é meio caminho entre o livro texto e uma palestra anotada. Assim, são usadas perguntas, atividades e questões para checar o aprendizado. O material escrito é a parte central dos cursos. Em sua maior parte são escritos por proeminentes acadêmicos. $\mathrm{O}$ melhor de um sistema de aprendizado como este é que, por exemplo, pode-se contar com especialistas mundiais em certos assuntos, quando é solicitado para que eles escrevam material para a OU. Se estes especialistas fossem convidados a dar uma palestra seria quase impossível, pois eles são muito ocupados. Assim podem-se retirar partes dos livros de pessoas eminentes de várias universidades ou obter idéias diretamente deles. Estes autores, primeiramente, produzem um rascunho, que é então passado para todos os membros da equipe do curso. Todos têm que ler, comentar e apontar modificações, caso seja necessário. O primeiro rascunho é passado apenas entre a equipe do curso. O segundo rascunho já é bem mais completo e será lido por leitores críticos e "avaliadores" de desenvolvimento. 
Os leitores críticos são os próprios tutores (orientadores), pessoas na área que trabalham para a OU meio período ou acadêmicos de outras instituições. Pelo fato de manterem cursos em outros países, a OU tenta conseguir pessoas de outros locais para ler os trabalhos, pois há coisas que podem não fazer sentido em alguns lugares. Um leitor crítico é alguém que conhece o assunto, que tem prática acadêmica. Os "avaliadores" de desenvolvimento são parecidos ao máximo com estudantes.

Resumidamente, todo livro passa pelo processo de ser escrito por uma pessoa, discutido e avaliado por outras pessoas, para depois voltar para à fase de recomposição para ser reescrito. $\mathrm{O}$ trabalho do autor principal vai sendo melhorado através deste processo.

Os alunos de administração têm um objetivo, eles querem melhorar as suas chances profissionais, se aperfeiçoar. Então, qualquer que seja o sistema, ele tem que tornar fácil a assimilação do conhecimento e a compreensão. Por isso o material impresso é melhor, pois traz mais flexibilidade. Pode-se ler em casa, ou no trem, por essa razão não é colocado grande volume de texto em conjunto. No entanto, também são usados alguns CD-ROMs que são comprados ou produzidos diretamente na universidade ou em associação com a BBC.

\section{Tecnologias Utilizadas}

No curso de MBA não há disponibilização de material on-line. Apesar de soar ultrapassado, a razão é crucial. Os alunos precisam de um material flexível, amigável, que não esteja em uma tela, que seja fácil de se ler, num trem ou avião.

Muitas pessoas da área de estudos à distância fazem as perguntas erradas a seus alunos. Eles perguntam "Vocês gostariam do material on-line?" E os alunos respondem "Claro!". Mas a pergunta que deveria ser feita é: "Vocês preferem o material on-line ou impresso?" A importância está na decisão. No entanto, a OU oferece um curso completamente criado para a Web. Neste curso, ao perguntarem aos alunos sobre o que faziam com o material, eles disseram que imprimiam cerca de $35 \%$.

Há estudos de cientistas que mostram que uma pessoa deve ler material impresso, pois o papel reflete a luz. É difícil ler no vídeo, que emite luz. Enfim, a tela do computador não é confortável para ser lida.

No momento estão pensando em colocar os textos em CD-ROM, mas não para a leitura principal. Segundo Mr. Wheatcroft, se os alunos quiserem produzir resumos de livros para si, o recurso eletrônico é uma boa idéia. Mas, um dos principais empecilhos na adoção do uso do CD-ROM é o problema dos direitos autorais. Se você disser que quer veicular algo eletronicamente, os autores consideram como comercial e cobram muito caro. Mas este problema está melhorando, pois as pessoas estão aceitando que este é o método atual de publicação. Os editores estão ficando mais realistas no que diz respeito a publicações eletrônicas, mas ainda há dificuldades.

Quando os clientes solicitarem, o material será disponibilizado na Internet. Atualmente a Open University está experimentando algo nessa área. Estão fazendo alguns cursos na IBM. A empresa quer os materiais on-line e, a universidade está encarando este curso como um piloto. Mas, o interessante é que estão ensinando gerentes de uma grande empresa de computadores, que por definição teriam que ser habilidosos no uso dos mesmos. No entanto, o uso que eles fizeram dos arquivos on-line foi mínimo. Eles tinham o material impresso e o acharam muito mais fácil de usar.

No futuro, a Open University pretende usar o computador mais para comunicação. Tentarão criar um equivalente distante do que você poderia fazer na universidade, por exemplo, você está no seu quarto lendo, e de repente não entende algo ou quer discutir aquilo com alguém. Então, você coloca o dedo marcando a página do livro, vai onde seus amigos estão e propõe: "Vamos discutir isso. Vamos falar sobre isso". Eletronicamente pode-se fazer algo parecido. 
O que já possuem no momento, através do sistema de conferências, é a possibilidade de contatar alguém, um dos tutores, por exemplo, e dizer: "Estou na página tal. Alguém pode me ajudar com isso?". Não é perfeito, pois às vezes você pode apenas ter um guia para uma discussão. O material pode ser colocado na rede, mas não para serem lidos lá. O que podem fazer é na conferência, colocar uma bandeirinha no texto e dizer: "Eu quero discutir isso". E outra pessoa pode falar sobre aquilo. Assim o texto on-line vai servir como base para se indicar o que se quer discutir. As pessoas primeiramente estudariam o texto normal e teriam como apontar a mesma coisa para ser usada em discussões eletronicamente.

No momento não estão usando muito a videoconferência, porque existem os tutores locais, onde quer que estejam os alunos, então haverá um seminário presencial, de cerca de 3 horas a cada seis semanas a nível local. Assim as pessoas se reúnem para participar do evento. Não usam tanto a videoconferências simplesmente porque no momento não há muitas pessoas que tenham condição de fazer o sistema utilizável. Mas, estão criando seus próprios sistemas, pois enxergam benefícios para o futuro. $\mathrm{Na}$ opinião do Mr. Wheatcroft daqui há duas ou três gerações de software, ou seja, daqui há uns três anos, o sistema e os computadores vão ser aperfeiçoados, com melhor sinal, e menores softwares, e aí sim o uso desta tecnologia será disseminado.

Mais de 150 cursos da OU estão usando a TI para apoiar a aprendizagem de diversas maneiras, incluindo aulas virtuais e grupos de discussão, a submissão eletrônica (e a marcação) das avaliações, materiais de ensino multimídia e conferência mediada por computador.

Em torno de 110.000 estudantes alunos lêem mais de 170.000 mensagens de e-mail por dia. Ao todo, quatorze cursos da OU já são disponibilizados através da Internet.

\section{Custo}

O custo de todo o sistema é muito alto. A OU possui milhares de alunos, o que justifica os gastos iniciais. O custo total de um curso de MBA é dez mil libras (£10.000) e em 2000, formou 1.400 alunos. As regras para a análise do custo em sistemas a distância foram apresentados por, entre outros, Rumble (1997). Deste estudo, as seguintes conclusões podem ser destacadas:

- Em sistemas convencionais de treinamento, o custo do ensino é calculado da forma tradicional, ou seja, variável em função do um número de estudante no sistema;

- Em contraste, em sistemas do treinamento da distância o custo de desenvolvimento de materiais pode ser considerado como um custo fixo e pode ser calculado com base na sobrevida do curso;

- De certa forma, e isso depende do custo da mídia escolhida, o sistema a distância deve tornar-se mais barato por a unidade de saída, do que um sistema tradicional.

Os custos da OUUK são significativamente mais baixos do que o de outras instituições, cerca de $42 \%$ do custo de outras universidades nos primeiros anos da graduação.

\section{Sistema de Avaliação e de Notas}

Os orientadores dão notas aos trabalhos e às provas e há um controle de qualidade muito rígido quanto aos critérios de correção adotados. 
Os orientadores dos cursos produzem um guia de notas, e todos têm um material completo, onde se encontram explicações sobre o que eles devem procurar ou sobre o que seria um trabalho médio ou ruim. Existem guias de nota que podem ter entre doze e quinze páginas.

O feedback dos trabalhos é considerado vital, porque o mais importante não está nos livros e sim nas suas avaliações. Num sistema de ensino à distância os trabalhos não são apenas para avaliação, eles são mais para ensinar.

É muito mais difícil dar notas em um bom trabalho do que em um trabalho ruim, porque no ruim você tem muito mais o que falar, é fácil fazer comentários. No bom trabalho, você tem que dizer algo para que o aluno ainda seja ajudado. Os orientadores devem ajudar todos os alunos, não só os mais fracos, ou os que estão com problemas.

O controle de qualidade varia um pouco, dado o grande número de orientadores e, alguns são mais severos nas notas do que outros, por esta razão a OU possui um sistema de monitoramento. A cada quinze trabalhos, dependendo da experiência do orientador, um é fotocopiado juntamente com os comentários e este são enviados para um monitor.

Se for um novo curso ou um novo orientador, três trabalhos são enviados. Um monitor avalia os trabalho de cinco ou seis orientadores dando outras notas a eles, para checar que eles estejam dando as notas corretamente e fazendo comentários adequados. Isto é enviado para os orientadores e para as pessoas que os empregam. $\mathrm{O}$ aluno recebe as notas dadas pelo orientador e pelo monitor e mais meia página de comentários.

A outra parte da avaliação é o processo de exames. Como a OUUK tem muitos alunos e muitos orientadores espalhados pelo mundo é necessário que, pelo menos um tipo de avaliação principal todos façam no mesmo período de tempo e, portanto, a antiquada prova de três horas de duração é o recurso mais realístico que é utilizado para esta escala. Há uma padronização para assegurar que todos sejam avaliados da mesma forma, onde quer que estejam no mundo. Desta forma, a maioria dos cursos tem um exame no final.

Todos os alunos que estão fazendo um determinado curso são avaliados no mesmo momento, não na mesma hora no relógio, mas num mesmo momento. Por exemplo, se é feita uma prova de manhã na Inglaterra, a mesma será feita à tarde na Índia e no começo da noite em outro lugar. Isto é feito para evitar fraudes, como já aconteceu em outras faculdades. Fraudes nas quais as provas eram passadas por fax de um lugar no mundo para outro. "Isto explicava porque alguns alunos entregavam a prova em cinco minutos e tiravam notas boas!”.

Todas as provas do mundo são mandadas para Milton Keynes. O processo de correção é dividido em três fases: a coordenação, a padronização e o grupo de premiação.

A coordenação é responsável por juntar todas as provas e distribuí-las para algumas pessoas para corrigi-las. Na próxima fase, de padronização, os alunos são analisados estatisticamente e não individualmente. São analisadas, por exemplo, as questões: supondo que na parte B da prova, as perguntas 2 e 3 sejam criadas com nível de dificuldade igual. Se no resultado acontecer de uma prova ser mais difícil que a outra, pode-se fazer um ajuste dizendo ao computador para acrescentar vinte por cento em todas as notas. O último processo é o grupo de premiação, onde se decide quem vai passar, ser reprovado ou receber um mérito ou distinção. 
No sistema educacional britânico, existem os chamados examinadores externos. Para cada curso universitário um professor sênior de outra instituição dá a palavra final sobre as notas dos alunos, ou seja, funciona como um árbitro final.

\section{CONCLUSÃO}

A experiência de mais de trinta anos da OUUK em educação a distância, associada a um elevado nível de excelência acadêmica, tem servido de modelo para instituições de todo mundo, que pretendem utilizar a educação a distância. O reconhecimento da excelência acadêmica foi confirmado, em 1994, quando a OU obteve o credenciamento do seu curso de MBA pela Association of MBAs (AMBA) e, em 2000, quando obteve a acreditação do Instituto de Qualidade Europeu (EQUIS) da European Foundation for Management Development (efmd).

A infra-estrutura do curso no âmbito pedagógico, desenho do curso, apresentação, formas de interação e ambiente de aprendizagem, associados à qualidade do material didático constituem a chave do sucesso do MBA da Open University.

Um dos elementos fundamentais nos cursos oferecidos pela Open University é uso de material impresso. Normalmente estes materiais são resultado de um processo estruturado, que envolve profissionais especializados em didática e especialistas nos assuntos a serem ensinados. $\mathrm{O}$ material utilizado num curso a distância tem que tornar fácil a assimilação do conhecimento e a compreensão, por isso o material impresso é melhor, pois traz mais flexibilidade para os alunos: pode-se ler em casa, ou no trem e, os alunos têm a liberdade de rever seus materiais quando bem entenderem ou necessitarem.

A estrutura do curso incentiva o aluno a estudar e pesquisar de modo independente e fortalece o aprendizado colaborativo, dinamizando a comunicação e a troca de informação entre os alunos, consolidando a aprendizagem através de atividades individuais ou em grupo. Nesta proposta de educação nota-se que são distribuídos igualmente cotas de responsabilidade, acessibilidade e oportunidade.

A preocupação com a avaliação da qualidade do ensino é percebida nas avaliações dos alunos. A universidade trata com muito rigor as questões referentes às avaliações e trabalhos dos alunos. Consideram o feedback destas avaliações como parte do processo de ensino/aprendizagem: "os trabalhos não são apenas para avaliação, eles são mais para ensinar". Ao final de todo processo de avaliação o aluno recebe meia página de comentários. Ao fazer isso, a OUUK torna o processo de notas transparente e, o aluno sente-se responsável pelo gerenciamento dos progressos obtidos.

Atualmente, a Open University está convertendo o seu sistema tradicional de educação a distância para uma abordagem eletrônica. Nesta mudança de opção estão considerando principalmente a experiência de aprendizado de seus alunos. Essa experiência mostra que, atualmente, os alunos preferem o material impresso ao material eletrônico, disponibilizado de forma on-line ou não.

Para tanto, calculam que cerca de quinze milhões de dólares serão investidos nos próximos cinco anos num programa intitulado Integrating New Systems and Technologies into Lifelong Learning, que tem com meta o desenvolvimento de novas tecnologias de ensino e aprendizagem.

Outros investimentos em tecnologia, como o que está sendo feito em associação com a UNext, que oferece cursos on-line de alta qualidade para negócios, apontam um caminho futuro a ser seguido. A 
estrutura de suporte ao aluno, bem como a disponibilização do conteúdo didático, devem convergir de forma gradual para a Internet.

O desafio para o futuro das novas tecnologias de aprendizagem será fortalecer a o senso de learning community, que é mais acessível, pessoal, interativo e integrado, e desta forma, diminuir a distância entre a open e distance learning.

\section{Artigo recebido em 19.05.2001. Aprovado em 06.06.2002}

\section{BIBLIOGRAFIA}

EVANS, T. \& NATION, D. Changing University Teaching: Kogan Page. London, 2000.

KEEGAN, Desmond. Foundations of Distance Education: Routledge. London, 1996.

KERKA, Sandra. Distance learning, the Internet, and the World Wide Web. ERIC Digest n ${ }^{\circ}$. 168. ED 395 214. Columbus: ERIC Clearinghouse on Adult, Career, and Vocational Education, the Ohio State University, 1996.

LOCKWOOD, F. \& GOOLEY, A. Innovation in Open \& Distance Learning: Kogan Page. London, 2001.

MAIA, Marta C. A Educação a Distância e as Escolas de Administração de Empresas. In: XI JORNADAS HISPANO-LUSAS DE GESTÃO CIENTÍFICA, 2001, Cárceres. Anais da XI Jornadas Hispano-Lusas de Gestão Científica. 2001.

- A Tecnologia de Informação como Ferramenta de Apoio ao Ensino. In: I TECNONEET 2000 - CONGRESSO INTERNACIONAL DE NUEVAS TECNOLOGIAS Y NECESSIDADES EDUCATIVAS ESPECIALES, 2000, Murcia. Anais do I TECNONEET 2000 Congresso Internacional de Nuevas Tecnologias y Necessidades Educativas Especiales. 2000.

. Estudo sobre a Informática no Ensino de Administração de Empresas. In: XXV ENANPAD - ENCONTRO DA ASSOCIAÇÃO NACIONAL DOS PROGRAMAS DE PÓSGRADUAÇÃO EM ADMINISTRAÇÃO, 1999, Foz do Iguaçu. Anais do XXV ENANPAD - Encontro da Associação Nacional dos Programas de Pós-Graduação em Administração. 1999.

. Internet $e$ o Ensino a Distância. In: I TECNONEET 2000 - CONGRESSO INTERNACIONAL DE NUEVAS TECNOLOGIAS Y NECESSIDADES EDUCATIVAS ESPECIALES, 2000, Murcia. Anais do I TECNONEET 2000 - Congresso Internacional de Nuevas Tecnologias y Necessidades Educativas Especiales. 2000.

. The use of Technology in Management Education. In: 2000 BALAS CONFERENCE - BUSINESS ASSOCIATION OF LATIN AMERICA, Caracas. Anais do 2000 BALAS Conference Business Association of Latin America. 2000.

MAIA, M. \& ABAL, M. Distance Training: Case Study in Europe. In: IV SIMPOI - SIMPÓSIO DE ADMINISTRAÇÃO DA PRODUÇÃO, LOGÍSTICA E OPERAÇÕES INTERNACIONAIS, 2001, Guarujá. Anais do IV SIMPOI - Simpósio de Administração da Produção, Logística e Operações Internacionais. 2001. 
MAIA, M. \& MEIRELLES, F. The Teaching of Operations Management in a Distance Course. In: IV SIMPOI - SIMPÓSIO DE ADMINISTRAÇÃO DA PRODUÇÃ̃O, LOGÍSTICA E OPERAÇÕES INTERNACIONAIS, 2001, Guarujá. Anais do IV SIMPOI - Simpósio de Administração da Produção, Logística e Operações Internacionais. 2001.

MAIA, M; MEIRELlES, F. \& ABAL, M. Distance Training: Case Study in Latin America. In: XXXVI CLADEA - CONSEJO LATINOAMERICANO DE ESCUELAS DE ADMINISTRACIÓN, 2001, Cidade do México. Anais do XXXVI CLADEA - Consejo Latinoamericano de Escuelas de Administración. 2001.

MAIER, P. \& WARREN, A. - Integr@ting Technology in Learning and Teaching, Kogan Page, London, 2000.

MEIRELLES, F. O Uso da Tecnologia de Informação para a Educação a Distância no Ensino Superior: Estudo dos Cursos de Administração de Empresas. Relatório de Pesquisa do NPP. Publicação da Escola de Administração de Empresas de São Paulo da Fundação Getulio Vargas (EAESP/FGV), São Paulo, 2002.

SCHLOSSER \& ANDERSON. Distance education: Review of the literature. Washington, DC: Association for Educational Communications Technology, 1994.

SCHON, D. - Educating the Reflective Practitioner: Jossey-Bass. San Francisco, 1987.

SCHREIBER, D. \& BERGE, Z. - Distance Training. How innovative organizations are using technology to maximize learning and meet business objectives: Jossey Bass. London, 1998.

SHERRY, L. Issues in distance learning. International Journal of Educational Telecommunications 1 (4): 337-65, 1995.

WEINSTEIN, P. Education goes the distance. Technology and Learning 17 (8): 24-25, 1997.

YIN, R. Estudo de caso: Planejamento e Métodos. 2a ed. Porto Alegre: Bookman, 2001. 